\title{
Application of different turbulence closure model for stratified tidal flows and salinity in an estuarine system
}

\author{
Wen-Cheng Liu ${ }^{\mathrm{a}, *}$, Ming-Hsi Hsu ${ }^{\mathrm{b}}$, Albert Y. Kuo ${ }^{\mathrm{b}}$ \\ ${ }^{a}$ Hydrotech Research Institute, National Taiwan University, No. 158 Chou-Shan Road, Taipei 10617, Taiwan, ROC. \\ ${ }^{\mathrm{b}}$ Department of Bioenvironmental Systems, Engineering, National Taiwan University, Taipei 10617, Taiwan, ROC.
}

Received 1 April 2001; accepted 14 September 2001

\begin{abstract}
Transient stratification in estuaries reflects competition between the stratifying influences of the vertical gravitational circulation and longitudinal density gradient by vertical shear, set against the mixing influence of, principally, tidally generated turbulence. A vertical (laterally averaged) two-dimensional model of an estuary, using seven different parameterizations of vertical mass and momentum mixing coefficients from the literature, is used to make general predictions about the nature of the time-dependent stratification, velocity field and salinity in an estuary. The downstream boundary, at the river mouth, is an $M_{2}$ tide with amplitude being half of the mean tidal range to force the model runs for numerical experiments. The results show the Mellor and Yamada scheme products larger stratification, density gradients and have less vertical mixing. Model calibration and verification is performed to use parameterization of mixing coefficients against observational data of salinity. The root-mean-square (RMS) errors and mean absolute errors are used as qualitative and quantitative criteria. The results show Park and Kuo scheme performs best. Mellor and Yamada scheme over-predict the amplitude of the stratification signal. The other schemes, such as Thompson, Lehfeldt and Bloss, Pacanowski and Philander, and Munk and Anderson, over-predict the maximum salinity. (C) 2002 IMACS. Published by Elsevier Science B.V. All rights reserved.
\end{abstract}

Keywords: Turbulence closure; Stratified flow; Hydrodynamic and salinity model; Estuarine stratification; Calibration and verification

\section{Introduction}

Tidal estuaries comprise the lowest reaches of the rivers where they enter the sea. Mixing in estuaries results from a combination of various effects such as tide, wind, the earth's rotation and inflow from rivers. The interaction between dense saline waters entering from the sea and the fresh water derived from the upland discharge gives rise to a wide spectrum of circulation pattern and estuarine mixing.

* Corresponding author.

E-mail address: wcliu@hy.ntu.edu.tw (W.-C. Liu). 
The flow and transport processes depend essentially on the tidal forcing, fresh water discharge and morphology. Stratified flow patterns with vertical circulatory motion, whose spatial and temporal extent depend on the tidal range, result form the mixing of fresh and salt water and may be modified by the surface wind shear. For well or partially mixed estuaries, stratified flow occurs only at slack tide in the region of the strongest longitudinal salinity gradient, while for stratified estuaries it may extend over the whole estuary throughout the tidal cycle. Turbulent transport in an estuary, and hence the distribution of temperature or concentration, is strongly affected by stratification in two ways. Vertical turbulent transport of momentum (eddy viscosity) determined the vertical distribution of horizontal velocity components. It, thus, governs horizontal advective transport, which in turn is balanced by the vertical turbulent transport of heat or solutes (eddy diffusivity). The mixing efficiency of these eddy fluxes depends on the hydrostatic stability of the actual system [8].

The application of two-dimensional models with different types of closure models to determine the tidal circulation in estuaries has been done in many part of the world. The multi-level breath averaged models developed for this purpose involve the parameterization of Reynold's stresses. Parameterization of eddy diffusivity has been carried out either by using simply the first order closure schemes $[1,4]$, a one equation model using algebraic mixing length [6,7], or by higher order turbulence closure schemes using prognostic equations for mixing length and turbulence energy for the three-dimensional models $[2,13]$. Studies on the inter-comparison of a range of turbulence models have been done for shelf regions [3,19]. Recently, Luyten et al. [9] presented a family of turbulence closure models for stratified shallow water flows with application to the Rhine outflow region. They deal with vertical one-dimensional modes of the stratification processes.

The aim of the present study is to simulate the salinity field and tidal currents by using different turbulence closure models. A number of different parameterizations for mixing coefficients that have appeared in the literature were adopted and tested. These include the simplest step function proposed by Thompson [18], through linear and nonlinear functions of gradient Richardson number, e.g. the Munk and Anderson [12] scheme, to the mores complex formulation, based on the equations for turbulent kinetic energy, of the Mellor and Yamada [10,11] level 2 scheme. Hence, laterally averaged multilevel model is developed and applied to the Tanshui River estuarine system in northern Taiwan. Turbulence closures schemes highlight a number of issues relating to their implementation, but they also provide an insight into the processes which are evident in estuarine observations.

\section{Model formulation}

A laterally integrated two-dimensional, real-time of hydrodynamics and water quality was developed for application to the tidal portion of the Tanshui River estuarine system. The model is based on the principles of conservation of volume, momentum and mass.

\subsection{Basic equations}

In a right-handed Cartesian coordinate system, with the $x$-axis directed seaward and the $z$-axis directed upward, the equation for the hydrodynamic portion of the model is as follows:

Laterally integrated continuity equation:

$$
\frac{\partial(u B)}{\partial x}+\frac{\partial(w B)}{\partial z}=q_{p}
$$


Laterally integrated momentum equation:

$$
\frac{\partial(u B)}{\partial t}+\frac{\partial(u B u)}{\partial x}+\frac{\partial(u B w)}{\partial z}=-\frac{B}{\rho} \frac{\partial p}{\partial x}+\frac{\partial}{\partial x}\left(A_{x} B \frac{\partial u}{\partial x}\right)+\frac{\partial}{\partial z}\left(A_{z} B \frac{\partial u}{\partial z}\right)
$$

Hydrostatic equation:

$$
\frac{\partial p}{\partial z}=\rho g \frac{\partial \eta}{\partial x}+g \int_{z}^{n} \frac{\partial p}{\partial x} \mathrm{~d} z
$$

Sectionaly integrated continuity equation:

$$
\frac{\partial}{\partial t}\left(B_{\eta} \eta\right)+\frac{\partial}{\partial x} \int_{-H}^{\eta}(u B) \mathrm{d} z=q
$$

Laterally integrated mass balance equation for salt:

$$
\frac{\partial(s B)}{\partial t}+\frac{\partial(s B u)}{\partial x}+\frac{\partial(s B w)}{\partial z}=\frac{\partial}{\partial x}\left(K_{x} B \frac{\partial s}{\partial x}\right)+\frac{\partial}{\partial z}\left(K_{z} B \frac{\partial s}{\partial z}\right)+S_{0}
$$

Equation of state:

$$
\rho=\rho_{0}(1+k s)
$$

Here $x$ is the seaward distance along the river axis, $z$ the upward distance in vertical direction, $t$ the time, $q_{p}$ the lateral inflow per unit lateral area, $q_{p}$ the lateral inflow per unit river length, $\eta$ the position of the free surface above the mean sea level, $s$ the laterally averaged salinity, $u$ and $w$ are the laterally averaged velocities in the $x$ and $z$ directions, respectively, $B$ the river width, $B_{\eta}$ the width at the free surface including side storage area, $H$ the total depth below the mean sea level, $p$ the pressure, $g$ the gravitational acceleration, $A_{z}$ and $K_{z}$ are turbulent viscosity and diffusivity, respectively, in $z$-direction, $A_{x}$ and $K_{x}$ are dispersion coefficients for momentum and mass, respectively, in the $x$-direction, $\rho$ and $\rho_{0}$ are the water density and freshwater density, respectively, $k$ the constant relating density to salinity $\left(=7.5 \times 10^{-4}\right), S_{0}$ the source and sink of salt due to exchange with the side storage area.

Eqs. (1), (2) and (5) are integrated over a layer of finite thickness and then solved with Eqs. (3), (4) and (6) by a two-time level, finite difference scheme with spatially staggered grid. The implicit treatment of the vertical diffusion terms results in a tri-diagonal matrix in the vertical direction. To improve the numerical stability, the pressure gradient term in Eq. (3) is evaluated using $\eta$ at a new time step. The method of solution is detailed in Park and Kuo [15,16] and Hsu et al. [5].

\subsection{Parameterizations of mixing coefficients}

It has long been held that the vertical mixing of mass and momentum are, in some sense, formally linked with water column stability through a quantity such as the gradient Richardson number. Based on, either theoretical arguments or empirical deductions, a number of functional relationships between the vertical eddy coefficients of mass, $K_{z}$, and momentum, $A_{z}$ have been proposed. For flow with two parallel plane boundaries in a wide channel of depth $h$, Rossby and Montgomery [17] proposed the mixing length form

$$
A_{z}=\phi_{\mathrm{m}} l^{2}\left|\frac{\partial u}{\partial z}\right|=\alpha Z^{2}\left(1-\frac{Z}{h}\right)^{2}\left|\frac{\partial u}{\partial z}\right| \phi_{\mathrm{m}}
$$




$$
K_{z}=\phi_{\mathrm{s}} l^{2}\left|\frac{\partial u}{\partial z}\right|=\alpha Z^{2}\left(1-\frac{Z}{h}\right)^{2}\left|\frac{\partial u}{\partial z}\right| \phi_{\mathrm{s}}
$$

where $Z$ is distance from the surface, $\alpha$ a constant to be determined empirically, $|\partial u / \partial z|$ the local value of vertical shear, $l$ the mixing length, $\phi$ variables are stability functions or damping functions which are parameterized in terms of gradient Richardson number. The mixing schemes to be considered are defined in the following equations:

Constant viscosity:

$$
A_{z}=K_{z}=0.06
$$

Thompson [18]:

$$
A_{z}=K_{z}=0.06, \quad \text { for } R_{i}<0.25, \quad A_{z}=K_{z}=0, \quad \text { for } R_{i} \geq 0.25
$$

Munk and Anderson [12]:

$$
\begin{aligned}
& A_{z}=0.06\left(1+10 R_{i}\right)^{-1 / 2} \\
& K_{z}=0.06\left(1+3.33 R_{i}\right)^{-3 / 2}
\end{aligned}
$$

Pacanowski and Philander [14]:

$$
\begin{aligned}
& A_{z}=10^{-2}\left(1+5 R_{i}\right)^{-2}+10^{-4} \\
& K_{z}=A_{z}\left(1+5 R_{i}\right)^{-1}+10^{-5}
\end{aligned}
$$

Lehfeldt and Bloss [8]:

$$
\begin{aligned}
& \phi_{\mathrm{m}}=\left(1+3 R_{i}\right)^{-1} \\
& \phi_{\mathrm{s}}=\left(1+3 R_{i}\right)^{-3}
\end{aligned}
$$

Park and Kuo [15]:

$$
\begin{aligned}
& A_{z}=\alpha Z^{2}\left(1-\frac{Z}{h}\right)^{2}\left|\frac{\partial u}{\partial z}\right|\left(1+\beta R_{i}\right)^{-1 / 2} \\
& K_{z}=\alpha Z^{2}\left(1-\frac{Z}{h}\right)^{2}\left|\frac{\partial u}{\partial z}\right|\left(1+\beta R_{i}\right)^{-3 / 2}
\end{aligned}
$$

where the constants ( $\alpha$ and $\beta$ ) are determined through model calibration. The gradient Richardson number $\left(R_{i}\right)$, a number of stability, is defined as,

$$
R_{i}=-\frac{g}{\rho}\left(\frac{\partial \rho}{\partial z}\right)\left(\frac{\partial u}{\partial z}\right)^{-2}
$$

Mellor and Yamada level 2 turbulence model [10,11]:

$$
A_{z}=\alpha^{\prime} Z^{2}\left(1-\frac{Z}{h}\right)^{2}\left|\frac{\partial u}{\partial z}\right|\left[\frac{\left(1-5.24 R_{f}\right)\left(1-4.27 R_{f}\right)}{\left(1-R_{f}\right)^{2 / 3}\left(1-4.48 R_{f}\right)}\right]^{3 / 2}
$$




$$
K_{z}=\frac{\alpha^{\prime}}{0.8} Z^{2}\left(1-\frac{Z}{h}\right)^{2}\left|\frac{\partial u}{\partial z}\right|\left[\frac{\left(1-5.24 R_{f}\right)^{3}\left(1-4.27 R_{f}\right)}{\left(1-R_{f}\right)^{2}\left(1-4.48 R_{f}\right)}\right]^{1 / 2}
$$

where

$$
R_{f}=0.656\left(R_{i}+0.178-\sqrt{R_{i}^{2}-0.323 R_{i}+0.0318}\right)
$$

where $\alpha^{\prime}$ is determined through model calibration.
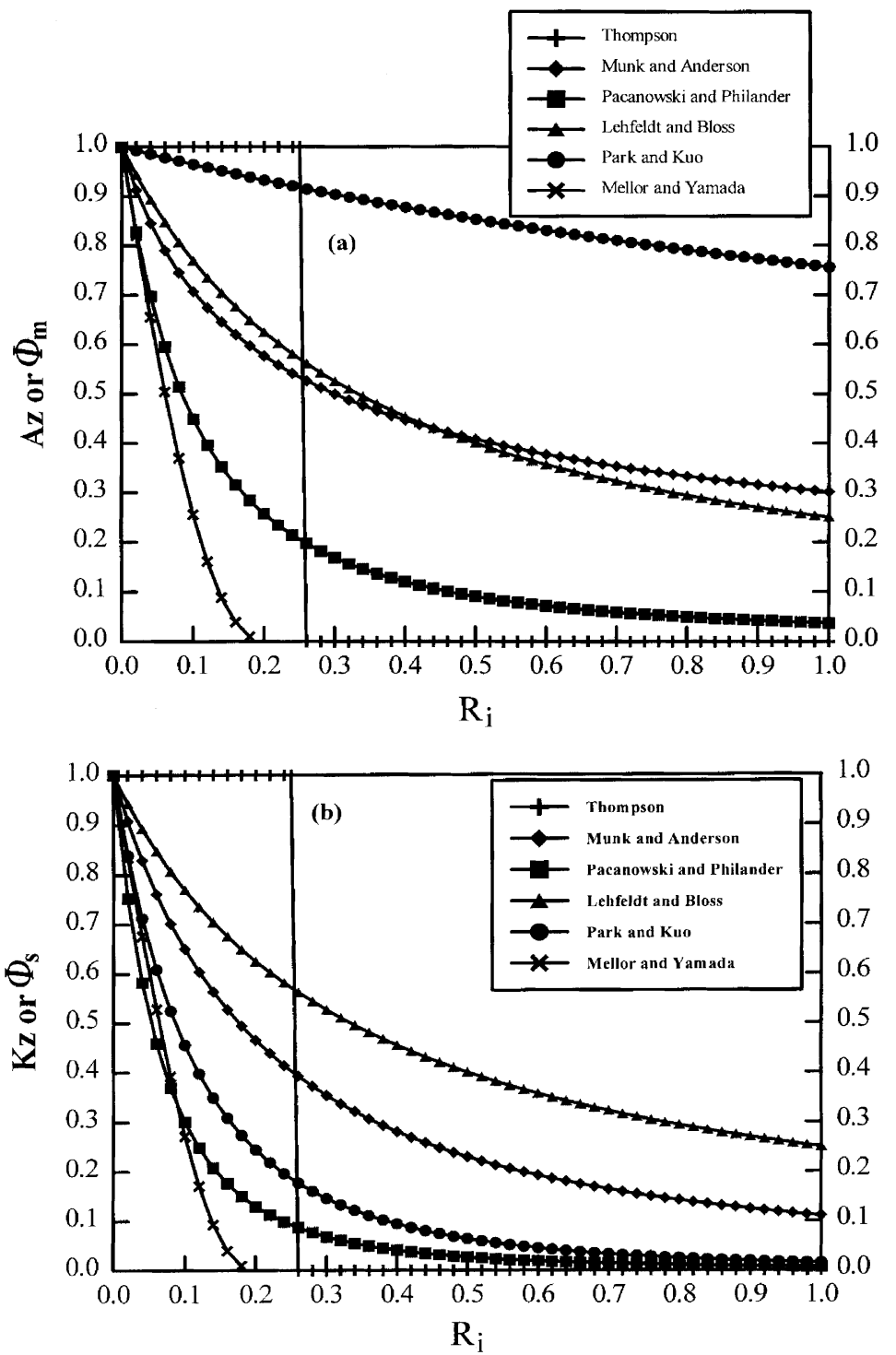

Fig. 1. Curves showing the behaviors of (a) the damping function or coefficient for momentum diffusion, $\phi_{\mathrm{m}}$ or normalized $A_{z}$, and (b) the damping function or coefficient for mass diffusion, $\phi_{\mathrm{s}}$ or normalized for each of the mixing parameterizations described in the text. 
In the Park and Kuo schemes, $\alpha=0.0115$ and $\beta=0.75$ are adopted. In the Mellor and Yamada level 2 turbulence model, $\alpha^{\prime}=2.0$ is used. Fig. 1(a) shows the behavior of $\phi_{\mathrm{m}}$ as a function of Richardson number, together with the behavior of all other momentum mixing coefficients outlined above. Similarly, Fig. 1(b) shows the behavior of all the mass mixing coefficients used here. There are seven parameterizations of mixing coefficients that are to be used and tested.

\section{Numerical experiment}

The model described in Section 2 has been applied to the tidal Tanshui River estuarine system. The Tanshui River is the largest tidal river in Taiwan. The entire river system has a drainage area of $2726 \mathrm{~km}^{2}$, and a total channel length of $327.6 \mathrm{~km}$. It consists of three major tributaries: the Tahan Stream, Hsintien Stream and Keelung River (Fig. 2). The downstream reaches of all the three tributaries are affected by the tide. Semidiurnal rides are the principal tidal constituents, with a mean tidal range of $2.22 \mathrm{~m}$ and a spring tidal range of $3.1 \mathrm{~m}$. The average river discharges at the tidal limits of the three major tributaries are 62.1, 72.7 and $26.1 \mathrm{~m}^{3} / \mathrm{s}$ for the Tahan Stream, Hsintien Stream and Keelung River, respectively.

In applying to the Tanshui River system, the model treats the Tanshui River and Tahan Stream as the main stem and Hsintien Stream and Keelung River as tributaries. The model is supplied with data describing the geometry of the Tanshui River system. The geometry in the vertical two-dimensional model is represented by width at each layer at the center of each grid well. A field survey in 1994 made by Taiwan Water Conservancy Agency collected the cross-sectional profiles at about $0.5 \mathrm{~km}$ interval along the tidal portion of the river. These profiles were used to schematize the river system. The

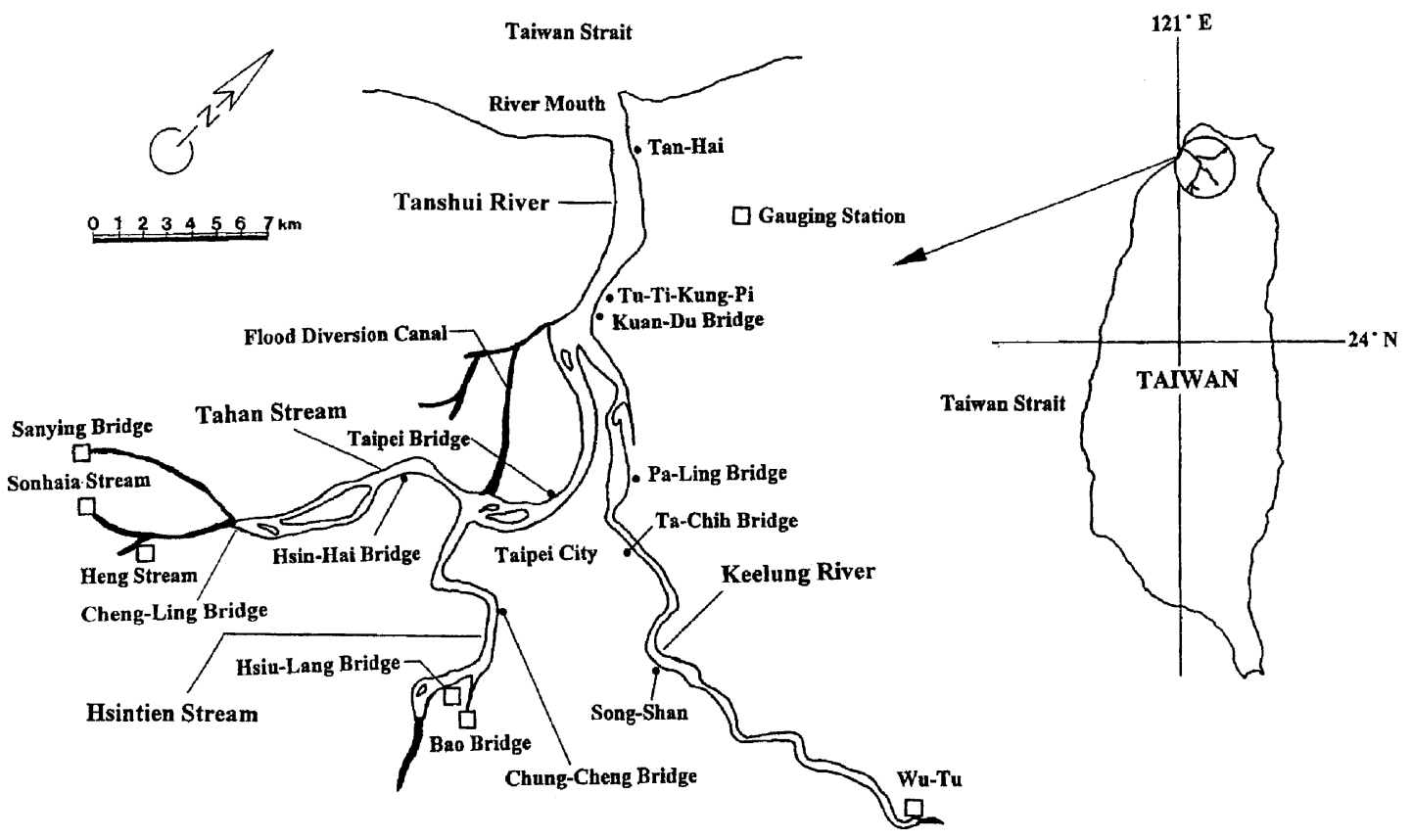

Fig. 2. Map of the Tanshui River estuarine system. 
three branches are divided into 33,14, and 37 segments, respectively, with a uniform segment length of $1 \mathrm{~km}$. The vertical layer thickness is $1 \mathrm{~m}$ for all the layers, except the surface layer which is variable, with $2 \mathrm{~m}$ at mean sea level. The maximum number of layers are 10 at the deepest section of the river.
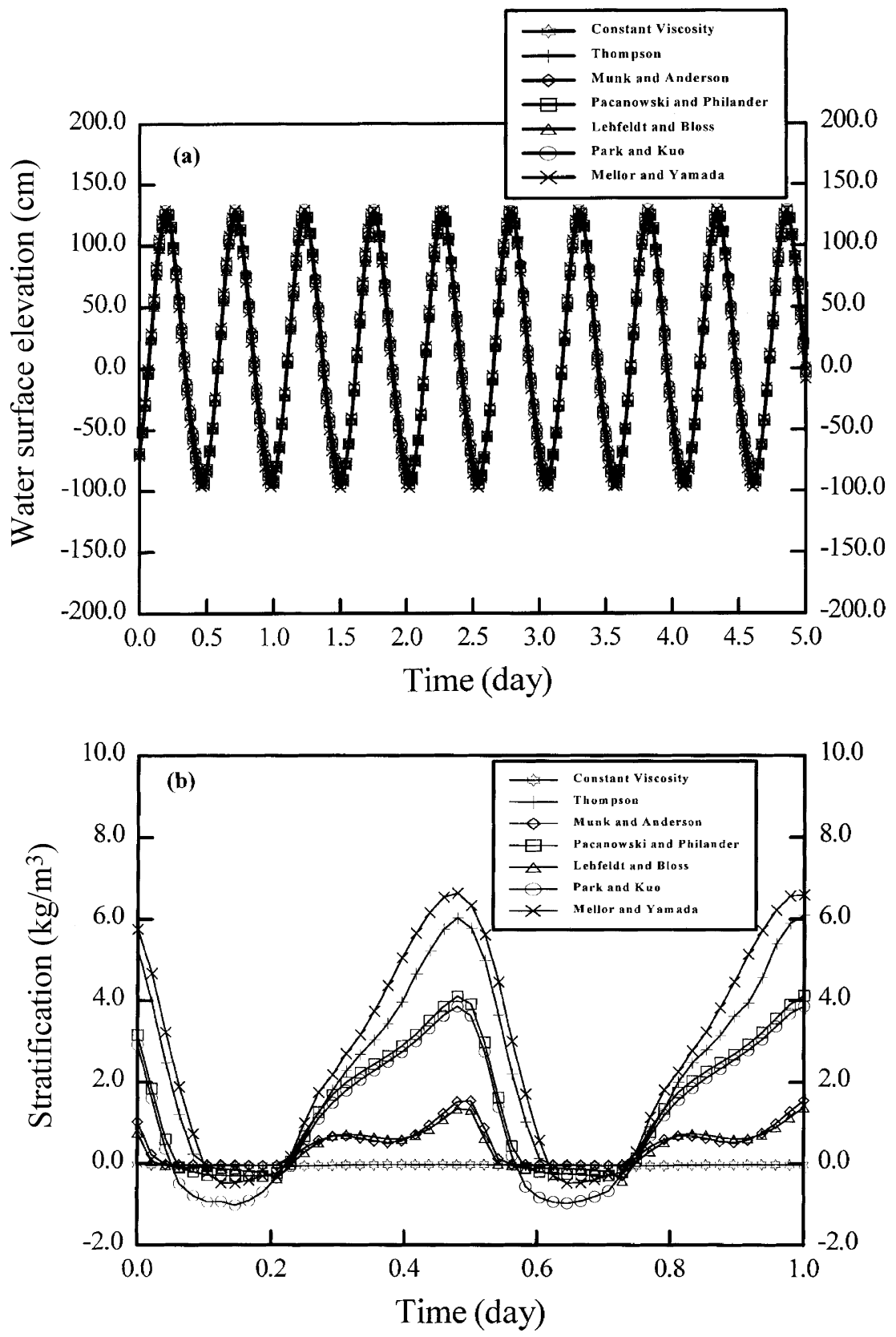

Fig. 3. Water surface elevation and stratification predicted by the seven mixing parameterizations (a) water surface elevation (b) stratification plotted on the same vertical scale for comparison of amplitudes. 
Numerical experiment was conducted with constant river discharge. The downstream boundary condition is an $M_{2}$ tide with amplitude being half of the mean tidal range, $111 \mathrm{~cm}$, calculated from 365 -day data measured at the Tanshui River mouth in 1994 and observed mean surface elevation of $10.7 \mathrm{~cm}$. For the low flow case, the model was run with the $Q_{75}$ freshwater discharges (a flow with an exceedance probability of 0.75 ) of $20.2,8.15$ and $3.61 \mathrm{~m}^{3} / \mathrm{s}$ at the upstream boundaries of the Tahan Stream, Hsintien Stream and Keelung River, respectively. The $25 \mathrm{ppt}$ at the Tanshui River mouth was used for boundary condition. The model was run for 30 tidal cycles to reach a dynamic equilibrium.
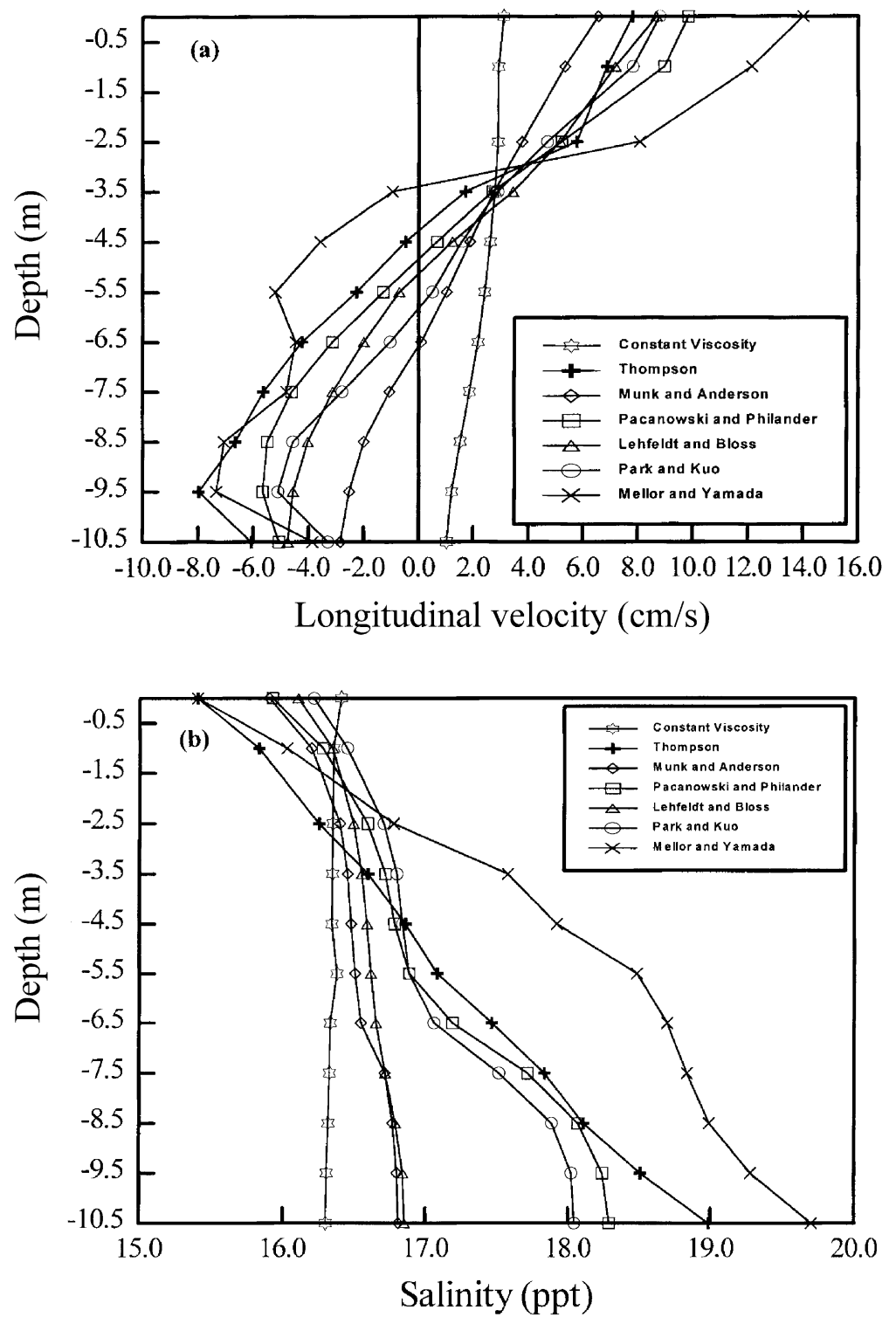

Fig. 4. Vertical profiles of (a) velocity (b) salinity at Ku-Du station. 
Fig. 3(a) presents the water surface elevation using different turbulence closure schemes at Kuan-Du station and shows that there is little discrepancy in water surface elevation. Results from the various mixing schemes are compared in Fig. 3(b) and shows the modeled stratification on the same vertical scale relative amplitudes. Clearly, the largest amplitude response occurs with the Mellor and Yamada scheme, as a result of the considerable reduction of mixing coefficients in the present of
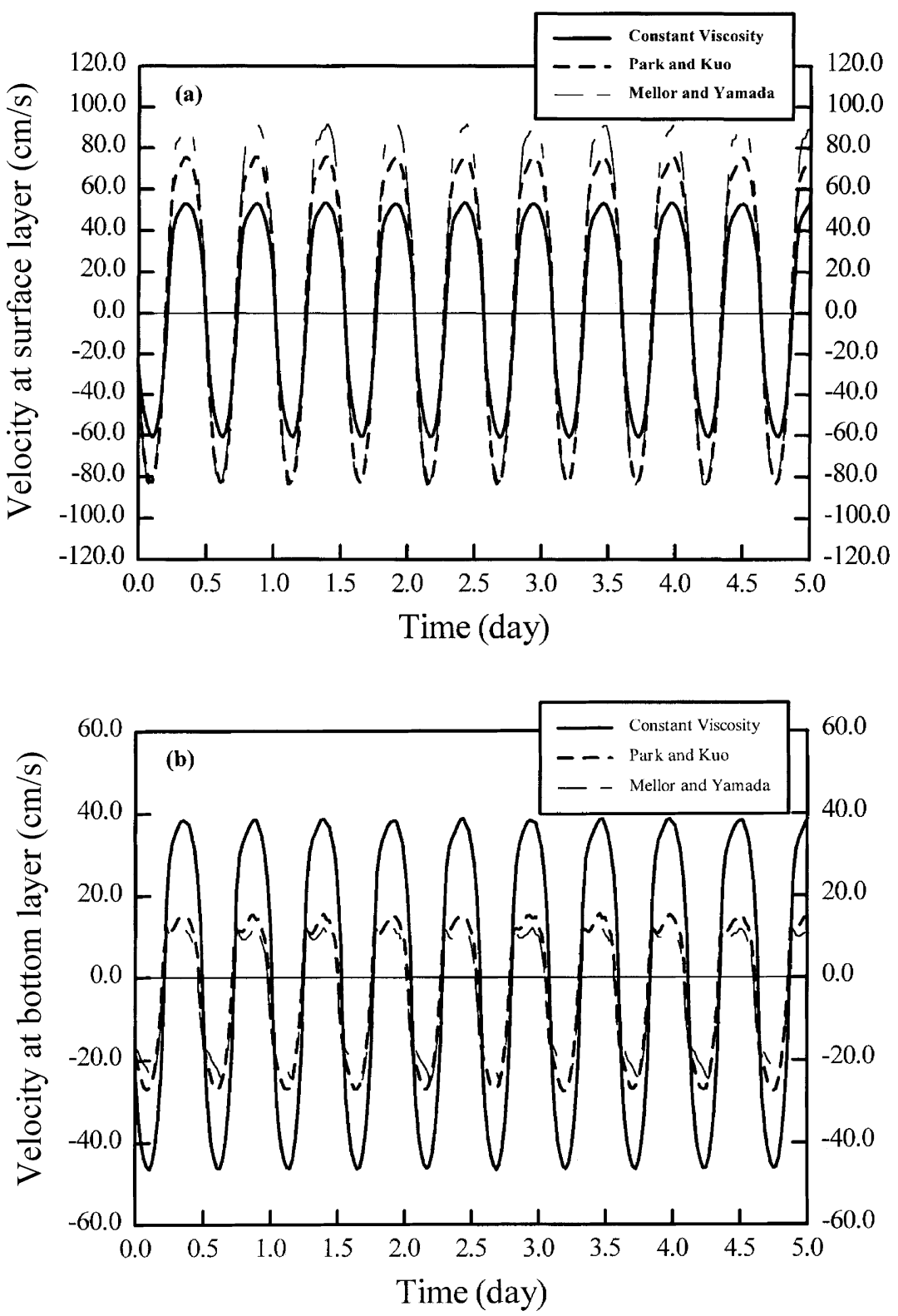

Fig. 5. Concurrent time series of (a) surface layer velocity and (b) bottom layer velocity. 
stratification. This allows large accelerations to develop which act to built vertical density structure very rapidly.

Fig. 4 presents velocity and salinity profiles obtained from all the seven mixing schemes at Kuan-Du station under the same forcing conditions. It shows the surface layer flow to seaward and bottom layer transport to upward except using constant viscosity. The largest velocity gradient and salinity gradient occurs with Mellor and Yamada scheme. Fig. 5 presents concurrent time series of surface and bottom currents using constant viscosity, Park and Kuo and Mellor Yamada schemes. There is smaller amplitude at the surface layer and larger amplitude at bottom layer using constant viscosity. There is an obvious distortion of the tidal currents that occur at the surface. This distortion arises because of the frictional decoupling between the upper and lower levels as the stratification develops. Its effect is to shorten the flood and lengthen the ebb phases, in keeping with the kind of distortion which is often observed in estuarine system.

\section{Model calibration and verification}

In most estuaries with a significant freshwater discharge, salinity may serve as an ideal natural tracer for calibrating of mixing processes. Salinity distribution in an estuary is affected by the tidal current, freshwater discharge, density circulation, as well as turbulent mixing processes. Therefore, the salinity distribution reflects the combined results of all the processes, and in turn it controls the density circulation and modified mixing process.

\subsection{Model calibration with different turbulence closure models}

The turbulent diffusion coefficients in turbulent closure models were calibrated with a simulation of salinity distributions from 15 March to June 1994. Three time-varying boundary conditions-freshwater

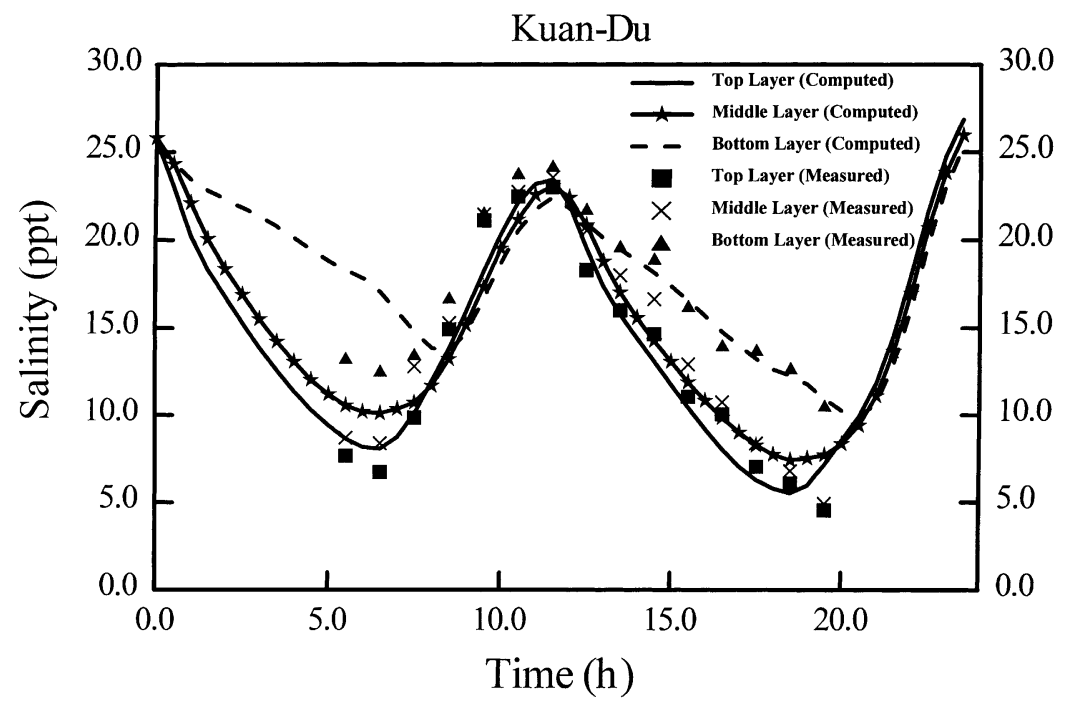

Fig. 6. Time series of salinity, as observed on 24 June 1994, and as predicted by Park and Kuo turbulence closure model. 
Table 1

Mean absolute errors and RMS errors of differences between computed and measured time series salinity data for model calibration in 24 June 1994

\begin{tabular}{|c|c|c|c|c|c|c|c|c|}
\hline \multirow[t]{3}{*}{ Layer } & \multicolumn{8}{|l|}{ Station } \\
\hline & \multicolumn{2}{|l|}{ Kuan-Du } & \multicolumn{2}{|l|}{ Taipei Bridge } & \multicolumn{2}{|l|}{ Hsin-Hai Bridge } & \multicolumn{2}{|l|}{ Pa-Ling Bridge } \\
\hline & $\begin{array}{l}\text { Mean absolute } \\
\text { error (ppt) }\end{array}$ & $\begin{array}{l}\text { RMS error } \\
(\mathrm{ppt})\end{array}$ & $\begin{array}{l}\text { Mean absolute } \\
\text { error (ppt) }\end{array}$ & $\begin{array}{l}\text { RMS error } \\
(\mathrm{ppt})\end{array}$ & $\begin{array}{l}\text { Mean absolute } \\
\text { error (ppt) }\end{array}$ & $\begin{array}{l}\text { RMS error } \\
\text { (ppt) }\end{array}$ & $\begin{array}{l}\text { Mean absolute } \\
\text { error (ppt) }\end{array}$ & $\begin{array}{l}\text { RMS error } \\
\text { (ppt) }\end{array}$ \\
\hline \multicolumn{9}{|c|}{ (a) Constant viscosity } \\
\hline Surface & 1.437 & 1.905 & 0.789 & 0.869 & 0.111 & 0.134 & 0.437 & 0.637 \\
\hline Bottom & 4.397 & 4.616 & 1.014 & 1.129 & 0.132 & 0.152 & 0.565 & 1.057 \\
\hline Middle & 1.932 & 2.355 & - & - & - & - & - & - \\
\hline \multicolumn{9}{|c|}{ (b) Thompson } \\
\hline Surface & 1.508 & 1.82 & 0.722 & 0.818 & 0.135 & 0.157 & 0.316 & 0.432 \\
\hline Bottom & 2.898 & 3.645 & 2.451 & 2.884 & 0.313 & 0.383 & 0.471 & 0.719 \\
\hline Middle & 2.635 & 3.398 & - & - & - & - & - & - \\
\hline \multicolumn{9}{|c|}{ (c) Munk and Anderson } \\
\hline Surface & 1.413 & 1.816 & 0.766 & 0.852 & 0.112 & 0.136 & 0.416 & 0.600 \\
\hline Bottom & 3.009 & 3.353 & 0.987 & 1.073 & 0.140 & 0.166 & 0.487 & 0.909 \\
\hline Middle & 1.828 & 2.241 & - & - & - & - & - & - \\
\hline \multicolumn{9}{|c|}{ (d) Pacanowski and Philander } \\
\hline Surface & 1.221 & 1.538 & 0.804 & 0.903 & 0.107 & 0.145 & 0.357 & 0.536 \\
\hline Bottom & 2.227 & 2.949 & 1.207 & 1.39 & 0.162 & 0.222 & 0.414 & 0.651 \\
\hline Middle & 1.578 & 1.910 & - & - & - & - & - & - \\
\hline \multicolumn{9}{|c|}{ (e) Lehfeldt and Bloss } \\
\hline Surface & 1.336 & 1.718 & 0.729 & 0.807 & 0.114 & 0.138 & 0.344 & 0.424 \\
\hline Bottom & 3.065 & 3.342 & 0.942 & 1.011 & 0.144 & 0.186 & 0.444 & 0.663 \\
\hline Middle & 1.689 & 2.063 & - & - & - & - & - & - \\
\hline \multicolumn{9}{|c|}{ (f) Park and Kuo } \\
\hline Surface & 1.126 & 1.388 & 0.780 & 0.819 & 0.132 & 0.161 & 0.491 & 0.900 \\
\hline Bottom & 1.874 & 2.541 & 1.552 & 1.776 & 0.218 & 0.270 & 0.436 & 0.813 \\
\hline Middle & 1.527 & 1.842 & - & - & - & - & - & - \\
\hline \multicolumn{9}{|c|}{ (g) Mellor and Yamada } \\
\hline Surface & 1.518 & 1.810 & 0.835 & 0.896 & 0.143 & 0.165 & 0.577 & 0.998 \\
\hline Bottom & 3.038 & 3.910 & 4.486 & 4.909 & 0.504 & 0.565 & 0.967 & 1.597 \\
\hline Middle & 3.197 & 3.877 & - & - & - & - & - & - \\
\hline
\end{tabular}


inflows through the upstream boundaries of the three branches, and the tide and salinity at river mouthwere specified for the model run. The upstream boundary conditions were specified with daily freshwater discharges at Cheng-Ling Bridge (Tahan Stream), Hsui-Lang Bridge (Hsintien Stream), Wu-Tu station (Keelung River). Hourly tidal elevation measured at the river mouth was used for the downstream boundary condition. The maximum salinity measured at the mouth on each survey data were linearly interpolated in time and used for the boundary condition, which specified the high tide salinity at each tidal cycle. An intensive survey was conducted by the Taiwan Water Conservancy Agency on 24 June 1994. Fig. 6 only shows a comparison of the time series salinity distributions in different layers at the Kuan-Du station using Park and Kuo turbulence closure model. The results show constant viscosity and Munk and Anderson schemes product well mixing conditions. The Mellor and Yamada scheme predicts the salinity in over-stratification comparison with the observation data. Table 1 lists the mean absolute errors and root-mean-square (RMS) errors that measure the differences between the computed and hourly measured data at various stations using different turbulence closure models. The overall comparison shows that the Park and Kuo scheme is best for model calibration.

Both the field data and model simulation indicate that the vertical salinity difference varies with the tidal phase from nearly 0 to as much as $6 \mathrm{ppt}$ at Kuan-Du. Hsu et al. [5] also showed that the spatial distribution of the tidal average salinity has a vertical difference of 1-2 ppt. Therefore, the Tanshui River estuary may be classified as a partially mixed estuary.

\section{Model verification with different turbulence closure models}

The model was verified with another set of field observation data. This was achieved with a model simulation of the prototype condition from 15 March to 30 April 1995. The data sources and procedure used to specify the boundary is similar to those of calibration simulation. Fig. 7 presents an example of

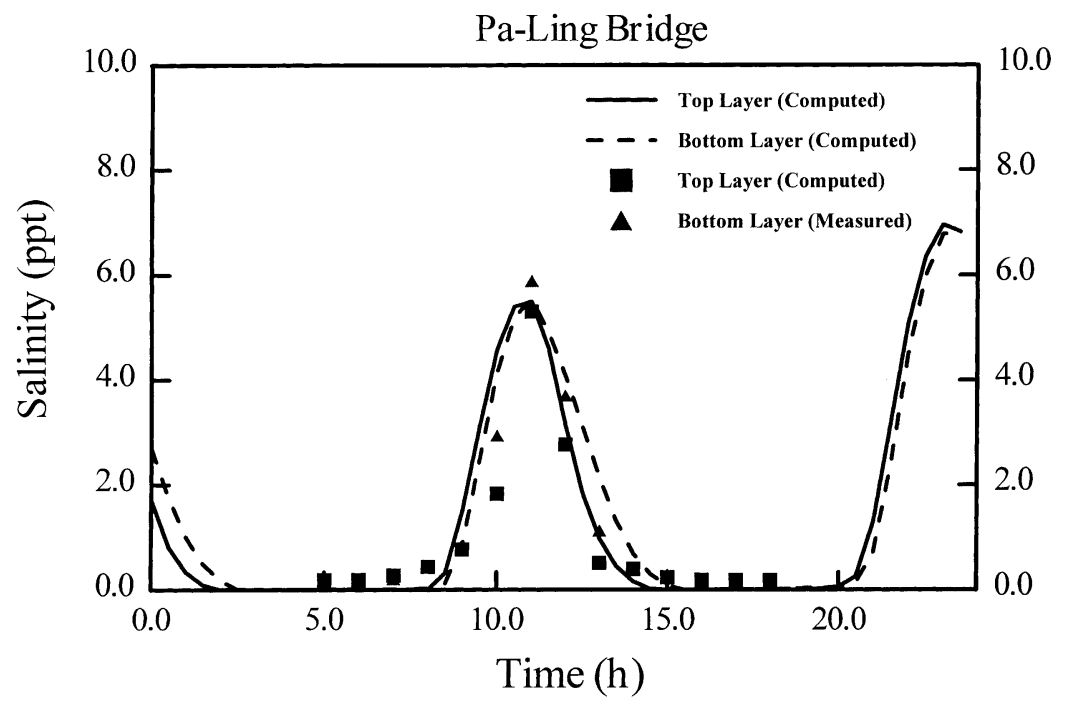

Fig. 7. Time series of salinity, as observed on 14 April 1995, and as predicted by Park and Kuo turbulence closure model. 
Table 2

Mean absolute errors and RMS errors of differences between computed and measured time series salinity data for model verification in 14 April 1995

\begin{tabular}{|c|c|c|c|c|c|c|c|c|}
\hline \multirow[t]{3}{*}{ Layer } & \multicolumn{8}{|l|}{ Station } \\
\hline & \multicolumn{2}{|l|}{ Kuan-Du } & \multicolumn{2}{|l|}{ Taipei Bridge } & \multicolumn{2}{|l|}{ Hsin-Hai Bridge } & \multicolumn{2}{|l|}{ Pa-Ling Bridge } \\
\hline & $\begin{array}{l}\text { Mean absolute } \\
\text { error (ppt) }\end{array}$ & $\begin{array}{l}\text { RMS error } \\
(\mathrm{ppt})\end{array}$ & $\begin{array}{l}\text { Mean absolute } \\
\text { error (ppt) }\end{array}$ & $\begin{array}{l}\text { RMS error } \\
(\mathrm{ppt})\end{array}$ & $\begin{array}{l}\text { Mean absolute } \\
\text { error (ppt) }\end{array}$ & $\begin{array}{l}\text { RMS error } \\
(\mathrm{ppt})\end{array}$ & $\begin{array}{l}\text { Mean absolute } \\
\text { error (ppt) }\end{array}$ & $\begin{array}{l}\text { RMS error } \\
(\mathrm{ppt})\end{array}$ \\
\hline \multicolumn{9}{|c|}{ (a) Constant viscosity } \\
\hline Surface & 1.012 & 1.239 & 0.827 & 0.938 & 0.097 & 0.110 & 0.574 & 0.883 \\
\hline Bottom & 2.335 & 2.550 & 1.015 & 1.088 & 0.092 & 0.107 & 0.804 & 1.231 \\
\hline Middle & 1.199 & 1.482 & - & - & - & - & - & - \\
\hline \multicolumn{9}{|c|}{ (b) Thompson } \\
\hline Surface & 0.767 & 1.023 & 0.794 & 0.901 & 0.111 & 0.129 & 0.488 & 0.751 \\
\hline Bottom & 1.167 & 1.520 & 1.310 & 1.465 & 0.190 & 0.250 & 0.497 & 0.719 \\
\hline Middle & 1.322 & 1.603 & - & - & - & - & - & - \\
\hline \multicolumn{9}{|c|}{ (c) Munk and Anderson } \\
\hline Surface & 0.845 & 1.133 & 0.803 & 0.914 & 0.105 & 0.115 & 0.545 & 0.842 \\
\hline Bottom & 2.082 & 2.282 & 1.008 & 1.080 & 0.106 & 0.125 & 0.683 & 0.984 \\
\hline Middle & 1.205 & 1.494 & - & - & - & - & - & - \\
\hline \multicolumn{9}{|c|}{ (d) Pacanowski and Philander } \\
\hline Surface & 0.786 & 1.007 & 0.811 & 0.923 & 0.103 & 0.118 & 0.348 & 0.475 \\
\hline Bottom & 1.103 & 1.344 & 1.076 & 1.205 & 0.109 & 0.141 & 0.308 & 0.363 \\
\hline Middle & 1.205 & 1.507 & - & - & - & - & - & - \\
\hline \multicolumn{9}{|c|}{ (e) Lehfeldt and Bloss } \\
\hline Surface & 0.918 & 1.146 & 0.793 & 0.900 & 0.106 & 0.122 & 0.354 & 0.453 \\
\hline Bottom & 2.007 & 2.218 & 0.918 & 1.010 & 0.098 & 0.132 & 0.410 & 0.519 \\
\hline Middle & 1.201 & 1.498 & - & - & - & - & - & - \\
\hline \multicolumn{9}{|c|}{ (f) Park and Kuo } \\
\hline Surface & 0.776 & 0.998 & 0.855 & 0.935 & 0.117 & 0.131 & 0.470 & 0.805 \\
\hline Bottom & 1.178 & 1.343 & 1.438 & 1.628 & 0.149 & 0.177 & 0.359 & 0.481 \\
\hline Middle & 1.187 & 1.463 & - & - & - & - & - & - \\
\hline \multicolumn{9}{|c|}{ (g) Mellor and Yamada } \\
\hline Surface & 0.833 & 1.060 & 0.866 & 0.974 & 0.114 & 0.131 & 0.364 & 0.487 \\
\hline Bottom & 1.545 & 1.816 & 1.456 & 1.682 & 0.238 & 0.296 & 0.476 & 0.684 \\
\hline Middle & 1.199 & 1.441 & - & - & - & - & - & - \\
\hline
\end{tabular}


comparison of the time series salinity distributions in different layers at the Pa-Ling Bridge using Park and Kuo turbulence closure model. The results show comparisons between the observed and modeled salinity is quite well predicted by the Park and Kuo scheme. The mean absolute errors and RMS errors of the differences between the computed and measured data are presented in Table 2. They range from 4.0 to $28.0 \%$ of the maximum salinity at corresponding station using Park and Kuo scheme.

\section{Conclusions}

In the present work, a breadth averaged multilevel numerical model is presented for the Tanshui River estuarine system. This paper uses a number of turbulent closure hypotheses, parameterizing mixing coefficients as functions of the gradient Richardson number, to make equivalent predictions about the time-dependent nature of estuarine stratification.

A single $M_{2}$ tide was used as a forcing function at the Tanshui River mouth and $Q_{75}$ freshwater discharges at the upstream boundaries, was conducted for the numerical experiments. The results show that the Mellor and Yamada scheme products larger stratification, density gradients and have less vertical mixing. Comparison between model and observations is judged against a set of qualitative and quantitative criteria and the results clearly show mixing scheme perform better than others. The Park and Kuo scheme produces the closest qualitative and quantitative fit to the observations. Mellor and Yamada scheme over-predict the amplitude of stratification signal. The other schemes, such as Thompson, Lehfeldt and Bloss, Pacanowski and Philander, and Munk and Anderson, over-predict the maximum salinity. Both, the field data and model simulation results indicate that the Tanshui River estuarine system may be classified as a partially mixed estuary.

As almost all the other investigators have notices, it is the turbulence closure model that limits the predictive capability of the hydrodynamic model and thus its applicability to other system. More understanding and better mathematical representation of the turbulent mixing processes are essential to improve the model capability. Nevertheless, the present model is a first step and it is useful for understanding many of estuarine processes. Further work is aimed at using higher order closure schemes and the development of three-dimensional model for the estuary.

\section{Acknowledgements}

The study is supported, in part, by National Science Council, Taiwan under Grant no. 90-2211-E002-082. The authors also thank the Taiwan Water Conservancy Agency for providing the prototype data.

\section{References}

[1] A.F. Blumberg, Numerical model of estuarine circulation, J. Hydraulic Div. ASCE 103 (1977) 295-310.

[2] A.F. Blumberg, G.L. Mellor, A description of a three-dimensional coastal ocean circulation model, in: N.S. Heaps (Ed.), Three-dimensional Coastal Ocean Models, American Geophysical Union, 1987, pp. 1-16.

[3] A.M. Davies, H. Gerritsen, An intercomparison of three-dimensional tidal hydrodynamic models of the Irish Sea, Tullus 46 (1994) 200-221.

[4] P. Hamilton, Modelling of salinity and circulation for the Columbia River estuary, Prog. Oceanogr. 25 (1990) $113-156$. 
[5] M.H. Hsu, A.Y. Kuo, J.T. Kuo, W.C. Liu, Study of tidal characteristics, estuarine circulation and salinity circulation in Tanshui River system (I) and (II), Technical Report No. 239 and 273, Hydrotech Research Institute, National Taiwan University, Taipei, Taiwan, 1996, 1997 (in Chinese).

[6] B. Johns, T. Oguz, The modelling of flow water through the Bosphorus, Dyn. Atm. Oceans 14 (1990) 229-258.

[7] B. Johns, G.S. Rao, S.K. Dube, P.C. Sinha, An application of a wind driven coastal upwelling model in the Bay of Bengal, Continental Shelf Res. 11 (1991) 295-319.

[8] R. Lehfeldt, S. Bloss, Algebraic turbulence model for stratified flows, in: J. Dronkers, van W. Leussen (Eds.), Physical Processes in Estuaries, 1988, pp. 278-291.

[9] P.J. Luyten, E. Deleesnijder, J. Ozer, K.G. Ruddick, Presentation of a family of turbulence closure models for stratified shallow water flows and preliminary application to the Rhine outflow region, Continental Shelf Res. 16 (1996) 101-130.

[10] G.L. Mellor, T. Yamada, A hierarchy of turbulence closure models for planetary boundary layers, J. Atm. Sci. 31 (1974) 1791-1806.

[11] G.L. Mellor, T. Yamada, Development of a turbulence closure model for geophysical fluid problems, Rev. Geophys. 20 (1982) 851-875.

[12] W.H. Munk, E.R. Anderson, Notes on a theory of the thermocline, J. Marine Res. 7 (1948) $276-295$.

[13] L.Y. Oey, G.L. Mellor, R.I. Hires, A Three-dimensional simulation of Hudson-Raritan estuary. Part I. Description of the model and model simulations, J. Phys. Oceanogr. 65 (1985) 1676-1692.

[14] R.C. Pacanowski, S.G.H. Philander, Parameterization of vertical mixing in numerical models of tropical oceans, J. Phys. Oceanogr. 11 (1981) 1443-1451.

[15] K. Park, A.Y. Kuo, A vertical two-dimensional model of estuarine hydrodynamics and water quality, Spec. Rep. App. Mar. Sci. Ocean Eng. No. 321, Virginia Institute of Marine Science, Gloucester Point, VA, 1993.

[16] K. Park, A.Y. Kuo, Numerical modeling of advection and diffusion transport in the Rappahannock estuary, in: Proceedings of 3rd International Conference of Estuarine and Coastal Modeling, ASCE, New York, 1994, pp. 461-474.

[17] C.G. Rossby, R.B. Montgomery, The layer of frictional influence in wind and ocean currents, Paper in Physical Oceanography and Meteorology, 1935.

[18] R.O.R.Y. Thompson, Efficiency of conservation of kinetic energy to potential energy by a breaking internal gravity wave, J. Geophys. Res. 85 (1980) 6631-6635.

[19] J. Xing, A.M. Davies, Application of turbulence energy models to the computation of tidal currents and mixing intensities in shelf edge regions, J. Phys. Oceanogr. 26 (1996) 417-447. 